\title{
Characteristics and Risk Factors Attributed to Coronary Artery Disease in Women Attended Health Services in Gaza-Palestine Observational Study
}

\author{
Yehia Abed1, Amal Jamee ${ }^{2}$ \\ ${ }^{1}$ Faculty of Public Health, Al Quds University, Gaza, Palestine \\ ${ }^{2}$ Cardiology Department, Al Shifa Hospital, Gaza, Palestine \\ Email: dramal08@yahoo.fr
}

Received 28 December 2014; accepted 15 January 2015; published 22 January 2015

Copyright (C) 2015 by authors and Scientific Research Publishing Inc.

This work is licensed under the Creative Commons Attribution International License (CC BY). http://creativecommons.org/licenses/by/4.0/

(c) (i) Open Access

\begin{abstract}
Coronary artery disease (CAD) is the leading cause of death in both sexes worldwide, and becomes number one killer in women due to many factors including increase in traditional risk factors, delays in apparition of symptoms, under estimation of diagnosis test and treatment. Our study aims to identify risk factors for coronary artery disease among women with chest pain underwent coronary angiography during years (2010-2013) in cardiology center. The study design is an observational among 688 women-aged 32 - 96 years; the mean age of our study population is 61 years. Risk factors are abstracted from patients' files. Women with documented coronaries disease tend to be older, have higher, systolic blood pressure, serum level of triglyceride, and impaired clearance creatinine. $59.4 \%$ of them are menopause with higher prevalence of hypertension and diabetes (58.6\% and 63.6\%). Significant positive association is found in women with myocardial infarction, unstable angina, stable angina and presence of obstructive coronary artery disease respectively $(89.6 \%, 82.3 \%, 59.1 \%)$ in opposite women presented with atypical chest pain have high prevalence of normal coronaries (95.7\%). About $57.6 \%$ have more than three risk factors, and $\mathbf{5 5 . 3 \%}$ are obese or overweight. In addition, $\mathbf{4 2 . 1 \%}$ of them have impaired systolic function. We conclude that cardiovascular risk factors are highly prevalent among Palestinians women in Gaza and the combination of risk factors is common. Interventions to minimize CAD in our population are needed.
\end{abstract}

\section{Keywords}

Coronary Artery Disease, Risk Factors, Chest Pain, Coronary Angiography, Gaza, Palestine

How to cite this paper: Abed, Y. and Jamee, A. (2015) Characteristics and Risk Factors Attributed to Coronary Artery Disease in Women Attended Health Services in Gaza-Palestine Observational Study. World Journal of Cardiovascular Diseases, 5, 9-18. http://dx.doi.org/10.4236/wjcd.2015.51002 


\section{Introduction}

Since 1997, awareness of women recognizing heart disease as the leading cause of death has mildly increased from $37 \%$ to $54 \%$ in 2009 [1]. It is now estimated that 1 of 2 women will die of heart disease or stroke in united state, compared with 1 in 25 women will die with breast cancer [2]-[4]. In Europe Cardiovascular, disease kills a higher percentage of women (55\%) than men (45\%) [5], due to sudden cardiac death prior to hospital arrival compared with men [6]. In Palestine, the burden of cardiovascular disease (CVD) increased. CVD was the first leading cause of death among Palestinian population in year 2013 [7]. But there are not many studies describing the presence of CAD in women undergoing coronary angiography (CAG). During the past years, several studies reported gender difference in the epidemiology, clinical manifestation, diagnosis, management and prevention of coronary artery disease (CAD) [8], and a greater mortality rate was noted in women [9] [10]. Women with ischemic symptoms are less likely than men to be referred for CAG and vascularization procedure and are diagnosed and treated at later stage, which results in a worse prognosis and increase mortality [11]-[14]. According to Framingham study, women have more frequent, episodes of angina, higher rate of hospitalization, high prevalence of myocardial infarction mortality, and higher rate of heart failure [15] [16]. Many studies have shown that women tend to differ in their presents symptoms. They have more atypical symptoms than male, which makes the diagnosis more difficult, with higher incidence of normal coronary arteries in catheterization procedure [17]. However, non-cardiac reasons for chest discomfort should be evaluated only after coronary disease has been ruled out [18].

The rate of CAD increases as the number of risk factors increases. Women with two or more risk factors have more prevalence of CAD compared with women without risk factors (50.2\%, 8.2\%) respectively [19].

This observational study was undertaken to define risk factors, symptoms of clinical presentation, and angiographic characteristics in women patients with chest pain admitted to cath lab in Gaza.

\section{Methodology}

An observational study included 862 female patients presented with chest pain underwent coronary angiography during years (2010-2013) at al Hayat center private cardiology clinic in Gaza. Angiographies had been performed by a cardiologist and scored for coronary vessels stenosis. Luminal stenosis more than 50\% at least in one vessel was considered as CAD, the number of involved vessels considered as the level of severity [20]. We gathered data on number of variable, including demographic, such as age, height and weight, characteristics such as CAD risk factors, family history, hyperlipedemia, Hypertension, Diabetes mellitus. Also data included presenting symptoms, such as myocardial infarction, stable or unstable angina, and atypical chest pain defined as nonexertional or prolonged discomfort unrelieved by rest. Cigarette smoking was excluded because it is not accepted practice for women in our society. Clinically we abstracted data about systolic and diastolic blood pressure, Electrocardiograms (ECG), echocardiography to evaluate left ventricular function. laboratory test including fasting blood sugar (FBS), triglycerides (TG) level, total cholesterol level, hemoglobin, and Clearance creatinine calculated according to Cockgroft-Gault equation $(140$-age $) \times$ weight $(\mathrm{kg}) / 72 \times$ serum creatinine (mg/dl) multiply by 0.85 , were collected. All data were obtained retrospectively from the patients files. Exclusion criteria were congenital heart disease, valvular heart disease, prior cardiac surgery or percutaneous coronary intervention. Overall, 174 participants were excluded. Therefore, we included 688 cases aged 32 - 96 years at the time of study presented to the center to perform coronary angiography for the first time. Statistical analyses were performed with SPSS (20.0), numerical variable were reported as the mean \pm SD, and categorical variables were presented as comparison between the study and control group. Chi-square test, $\mathrm{t}$ test and Anova were used to compare means between different groups; Logistic regression analysis was performed to determine the independent predictor of CAD. All test of statistical significance were considered significant at 0.05 levels. The ethical committee (Helsinki) in Gaza approved the study.

\section{Results}

Our study population number was 688 women, in "Table 1" catheterization data showed that 55.2\% had significant CAD that was defined as $\geq 50 \%$ luminal narrowing, and $44.8 \%$ had no coronary artery disease, the mean age of study population was 61 years. Women with obstructive CAD tend to be older compared to women with normal coronary respectively $(63.6,57.9)$ and the difference was statically significant $(\mathrm{P}$ value $<0.001)$. There 
Table 1. Baseline demographic and clinical characteristics of study population.

\begin{tabular}{|c|c|c|c|c|c|c|c|c|}
\hline \multirow[t]{2}{*}{ Characteristics } & \multicolumn{2}{|c|}{$\begin{array}{c}\text { Obstructive } \\
\text { coronary artery disease }\end{array}$} & \multicolumn{2}{|c|}{$\begin{array}{l}\text { Non obstructive } \\
\text { coronary artery disease }\end{array}$} & \multicolumn{2}{|c|}{ Total } & \multirow[t]{2}{*}{$P$ value } & \multirow[t]{2}{*}{ OR $(95 \% \mathrm{CI})$} \\
\hline & No & $\%$ & No & $\%$ & No & $\%$ & & \\
\hline Total study population & 380 & 55.2 & 308 & 44.8 & 688 & 100 & & \\
\hline Age mean/years & \multicolumn{2}{|c|}{$63.61 \pm 9.3$} & \multicolumn{2}{|c|}{$57.96 \pm 9.8$} & \multicolumn{2}{|c|}{$61.09 \pm 9.9$} & 0.001 & \\
\hline Mean BMI kg/m² & \multicolumn{2}{|c|}{$34.9 \pm 5.7$} & \multicolumn{2}{|c|}{$35.1 \pm 6.3$} & \multicolumn{2}{|c|}{$35.05 \pm 5.9$} & 0.789 & \\
\hline Normal (18.5 - 25) & 9 & 52.9 & 8 & 47.1 & 17 & 100 & 0.925 & 1 \\
\hline Overweight (25 - 29.9) & 63 & 53.8 & 54 & 46.2 & 117 & 100 & 0.925 & $1.1(0.3-3.2)$ \\
\hline Obese $\geq 30$ & 308 & 55.6 & 246 & 44.4 & 554 & 100 & 0.625 & $1.1(0.4-3.2)$ \\
\hline \multicolumn{9}{|l|}{ Menopause } \\
\hline Yes & 348 & 59.4 & 238 & 40.6 & 586 & 100 & 0.001 & $3.2(2.0-5.0)$ \\
\hline No & 32 & 31.4 & 70 & 68.6 & 102 & 100 & & \\
\hline \multicolumn{9}{|l|}{ HTN } \\
\hline Yes & 330 & 58.6 & 233 & 41.4 & 563 & 100 & 0.001 & $2.1(1.4-3.1)$ \\
\hline No & 50 & 40 & 75 & 60 & 125 & 100 & & \\
\hline \multicolumn{9}{|l|}{ Diabetes } \\
\hline Yes & 267 & 63.6 & 153 & 36.4 & 420 & 100 & 0.001 & $2.4(1.8-3.3)$ \\
\hline No & 113 & 42.2 & 155 & 57.8 & 268 & 100 & & \\
\hline SBP mean SD mmHg & \multicolumn{2}{|c|}{$147.9 \pm 19.23$} & \multicolumn{2}{|c|}{$142.39 \pm 20.68$} & \multicolumn{2}{|c|}{$144.9 \pm 20.0$} & 0.002 & \\
\hline DBP mean SD mmHg & \multicolumn{2}{|c|}{$82.92 \pm 9.42$} & \multicolumn{2}{|c|}{$81.54 \pm 10.5$} & \multicolumn{2}{|c|}{$82.3 \pm 9.9$} & 0.070 & \\
\hline Total cholesterol mean (mg/dl) & \multicolumn{2}{|c|}{$193.9 \pm 51.6$} & \multicolumn{2}{|c|}{$189.98 \pm 45.93$} & \multicolumn{2}{|c|}{$191.43 \pm 48.7$} & 0.643 & \\
\hline Triglycerides level mean (g/dl) & \multicolumn{2}{|c|}{$229.2 \pm 127.7$} & \multicolumn{2}{|c|}{$186.48 \pm 85.86$} & \multicolumn{2}{|c|}{$207.49 \pm 108.1$} & 0.001 & \\
\hline Haemoglobine mean (g/dl) & \multicolumn{2}{|c|}{$11.69 \pm 1.25$} & & 1.25 & & & 0.109 & \\
\hline Clearance creatinine mean & 94.0 & 1.63 & 106 & 8.59 & & 0.6 & 0.002 & \\
\hline Chest pain & & & & & & & & \\
\hline Atypical angina pain & 9 & 4.3 & 202 & 95.7 & 211 & 100 & & \\
\hline Myocardial infarction & 112 & 89.6 & 13 & 10.4 & 125 & 100 & $\cap 0 \cap 1$ & \\
\hline Unstable angina & 181 & 82.3 & 39 & 17.7 & 220 & 100 & 0.001 & \\
\hline Stable angina & 78 & 59.1 & 54 & 40.9 & 132 & 100 & & \\
\hline Electrocardiogram & & & & & & & & \\
\hline Normal & 101 & 40.1 & 151 & 59.9 & 252 & 100 & 0.001 & $2.7(1.9-3.7)$ \\
\hline Abnormal & 279 & 64.0 & 157 & 36.0 & 436 & 100 & & \\
\hline Left ventricular function (EF \%) & & & & & & & & \\
\hline $\mathrm{EF}<55 \%$ & 252 & 65.6 & 132 & 34.4 & 384 & 100 & 0.001 & $2.6(1.9-3.5)$ \\
\hline$E F \geq 55 \%$ & 128 & 42.1 & 176 & 57.9 & 304 & 100 & & \\
\hline
\end{tabular}

was no difference in the mean BMI between the two groups indicating that the severity of obesity was the same. women with documented CAD had higher Systolic blood pressure, serum level of triglyceride, and impaired clearance creatinine and difference between means for all these indicators reached statistical significant level (P value $<0.001)$. Minor difference was noted between the two groups in diastolic blood pressure, total cholesterol level and hemoglobin level. To continue our results, menopause was found among 59.4\% of subject group vs. 
$40.6 \%$ in control group and our data found that menopause women have the chance 3.2 times to develop CAD and difference between the two means reach statistical significant level ( $\mathrm{P}$ value $<0.001)$. Hypertension and diabetes were higher in CAD group respectively $(58.6 \%, 63.6 \%)$ and the risk for these two risk factors were (2.1, $2.4)$ the difference was statically significant $P$ value $<0.001$. In addition significant Positive correlation was found in women with myocardial infarction, unstable angina, stable angina and presence of obstructive coronary artery disease respectively $(89.6 \%, 82.3 \%, 59.1 \%)$ in opposite women presented with atypical chest pain had high prevalence of normal coronaries (95.7\%), the difference between groups reached a statistical significant level P value less than 0.001 . Also 64\% of women with approved CAD had an abnormal ECG findings compared with women normal ECG and the difference was statistically significant P value less than 0.001 OR (CI) was 2.7 (1.9 - 3.7). Left ventricular function estimated by EF was better in women with normal coronaries than women with CAD respectively (57.9\%, 42.1\%) OR (CI) was 2.6 (1.93 - 3.5).

To continue our summary statistics presented in "Table 2" women with unstable angina and myocardial infarction tend to be older than women with other clinical presentation and the difference did not reached a statistical significant level, $(\mathrm{P}$ value $=0.063)$. The prevalence of HTN was higher in women with unstable and stable angina (88.2\%, 86.4\%), respectively. However, diabetes mellitus and menopause were more prevalent in patients with myocardial infarction and unstable angina (68.8\%, 94.4\%), (68.6\%, 92.3\%) respectively, also we observed that impaired systolic left ventricular function was more present in patients with myocardial infarction and unstable angina $(74.4 \%, 45.5 \%)$ respectively, and all these relative risk factors represents statically significant difference. In addition, there was minors' difference in other risk factors like high level of Triglyceride, Cholesterol level and BMI $\geq 25 \mathrm{~kg} / \mathrm{m}^{2}$.

In Table 3, we studied the relationship with cluster of risk factors and number of vessels disease, based upon, the results of coronary angiography. We gather the major significant risk factors such as Hypertension, Diabetes, high TG level, and menopause. Patients with no risk factors, had (4.5\%) normal coronary, and (2.6\%) one vessel disease, however women with one risk factors had $17.9 \%$ normal coronaries (7.1\%) one vessel and (9.3\%, 6.5\%) two and three vessels disease respectively. Also, we noted that when the number of risk factors increase the number of vessels disease increase (multivessels define as $\geq 50 \%$ narrowing in at least two vessels), and all of these variables represent statistical significant level $P$ value $<0.001$. In addition, Table 3 demonstrated the relationship between number of stenosis vessels and the clinical presentation, we noted that $65.6 \%$ of patients with atypical chest pain had normal coronaries; an only $2.6 \%$ had one vessel disease. Study population how had myocardial infarction, had high prevalence of coronary disease (25.3\%, 33.9\%, 30.6\%) respectively, and only $4.2 \%$ had normal coronaries; this is due to early thrombolytic therapy. In other hand, patients with unstable angina had multivessels disease, and most of patients with chronic stable angina had one vessels disease (28.6\%), mostly these patients are under aggressive anti anginal medications including statine. The difference between different data was statistically significant $\mathrm{P}$ value $<0.001$.

All the variables proved to have statistical significance association with the occurrence of CAD are included as independent variables in the logistic regression analysis demonstrated in Table 4 and the results revealed that age and diabetes are working independently on development of CAD in women.

Table 2. The prevalence of conventional risk factors in patients with different clinical presentation.

\begin{tabular}{|c|c|c|c|c|c|c|c|c|c|c|c|}
\hline \multirow[t]{2}{*}{ Risk factors } & \multicolumn{2}{|c|}{$\begin{array}{l}\text { Atypical chest } \\
\text { pain }\end{array}$} & \multicolumn{2}{|c|}{$\begin{array}{l}\text { Myocardial } \\
\text { infarction }\end{array}$} & \multicolumn{2}{|c|}{ Unstable angina } & \multicolumn{2}{|c|}{ Stable angina } & \multicolumn{2}{|c|}{ Total } & \multirow[t]{2}{*}{ P value } \\
\hline & No & $\%$ & No & $\%$ & No & $\%$ & No & $\%$ & No & $\%$ & \\
\hline Mean age & \multicolumn{2}{|c|}{$57.3 \pm 9.6$} & \multicolumn{2}{|c|}{$63.3 \pm 9.2$} & \multicolumn{2}{|c|}{$63.7 \pm 9.3$} & \multicolumn{2}{|c|}{$60.8 \pm 10.1$} & \multicolumn{2}{|c|}{$61.9 \pm 9.9$} & 0.063 \\
\hline Hypertension & 159 & 75.4 & 96 & 76.8 & 194 & 88.2 & 114 & 86.4 & 563 & 81.8 & 0.001 \\
\hline Diabetes & 100 & 47.4 & 86 & 68.8 & 151 & 68.6 & 83 & 62.9 & 420 & 61.0 & 0.001 \\
\hline Menopause & 157 & 74.3 & 118 & 94.4 & 203 & 92.3 & 108 & 81.8 & 586 & 85.2 & 0.000 \\
\hline HFCAD & 56 & 26.5 & 36 & 28.2 & 57 & 25.9 & 37 & 28.0 & 186 & 27.2 & 0.934 \\
\hline High triglyceride & 58 & 65.9 & 24 & 68.6 & 50 & 72.5 & 34 & 70.8 & 166 & 69.2 & 0.836 \\
\hline High cholesterol & 29 & 33.0 & 15 & 42.9 & 24 & 34.8 & 23 & 48.9 & 91 & 33.0 & 0.263 \\
\hline $\mathrm{BMI} \geq 25 \mathrm{~kg} / \mathrm{m}^{2}$ & 211 & 98.1 & 119 & 95.2 & 215 & 97.9 & 132 & 98.5 & 671 & 97.5 & 0.303 \\
\hline LV function EF & 92 & 43.6 & 93 & 74.4 & 139 & 63.2 & 60 & 45.5 & 384 & 55.8 & 0.001 \\
\hline
\end{tabular}


Table 3. Relation of risk factors group and clinical presentation with coronary angiographic date.

\begin{tabular}{|c|c|c|c|c|c|c|c|c|c|c|c|c|}
\hline & \multirow{2}{*}{ Group of risk factors } & \multicolumn{2}{|c|}{ Normal vessels } & \multicolumn{2}{|c|}{ One vessel } & \multicolumn{2}{|c|}{ Two vessels } & \multicolumn{2}{|c|}{ Three vessels } & \multicolumn{2}{|c|}{ Total } & \multirow[t]{2}{*}{$P$ value } \\
\hline & & No & $\%$ & No & $\%$ & No & $\%$ & No & $\%$ & No & $\%$ & \\
\hline \multirow{4}{*}{$\begin{array}{l}\text { Group of } \\
\text { risk factors }\end{array}$} & No risk factor & 14 & 4.5 & 4 & 2.6 & 0 & 0 & 0 & 0 & 18 & 2.6 & \multirow{4}{*}{$<0.001$} \\
\hline & 1 risk factors & 55 & 17.9 & 11 & 7.1 & 11 & 9.3 & 7 & 6.5 & 84 & 12.2 & \\
\hline & 2 risk factors & 99 & 32.1 & 39 & 25.3 & 26 & 22 & 26 & 24.1 & 190 & 27.9 & \\
\hline & $\geq 3$ risk factors & 140 & 45.5 & 100 & 64.9 & 81 & 68.6 & 75 & 69.4 & 396 & 57.6 & \\
\hline \multirow{4}{*}{$\begin{array}{c}\text { Clinical } \\
\text { diagnosis }\end{array}$} & Atypical chest pain & 202 & 65.6 & 4 & 2.6 & 4 & 3.4 & 1 & 0.9 & 211 & 30.7 & \multirow{4}{*}{$<0.001$} \\
\hline & Myocardial infraction & 13 & 4.2 & 39 & 25.3 & 40 & 33.9 & 33 & 30.6 & 125 & 18.2 & \\
\hline & Unstable angina & 39 & 12.7 & 67 & 43.5 & 59 & 50.0 & 55 & 50.9 & 220 & 32.0 & \\
\hline & Stable angina & 54 & 17.5 & 44 & 28.6 & 15 & 12.7 & 19 & 17.6 & 132 & 19.2 & \\
\hline
\end{tabular}

Table 4. Logistic regression analysis with coronary artery disease as dependent variable and other major risk factors as independent variables.

\begin{tabular}{cccc}
\hline Variables & B & P value & OR (95\% CI) \\
\hline Age & 0.050 & 0.004 & $1.1(1.01-1.08)$ \\
Hypertension & 0.488 & 0.171 & $1.6(0.8-3.2)$ \\
Diabetes mellitus & 0.857 & 0.005 & $2.4(1.3-4.3)$ \\
Menopause & 0.328 & 0.485 & $1.4(0.5-3.4)$ \\
Triglyceride & 0.365 & 0.240 & $1.4(0.8-2.6)$ \\
Constant & -4.442 & 0.000 & \\
\hline
\end{tabular}

\section{Discussion}

Our study analyzed data about population of patients attended coronary angiography service in Gaza, with mean age 61 years. Women with documented CAD tend to be older with mean age 64 years. Many study are in line with our results and showed that advancing age is a risk factors of CAD in women $>55$ [8]. The National cholesterol Education Panel adult treated Panel Ш (NCEP ATPШ) consider the age of 55years as a risk for women [21]. In Nurses' health study in USA, the age adjusted relative risk for non-fatal myocardial infarction and fatal CAD among female with a parental history of acute Myocardial infarction before age 60 years were 2.8 and 5.0 respectively indicated age as risk factor for CAD [22].

The prevalence of CAD in our study population was $55.2 \%$ compared to $44.8 \%$ with normal coronaries, our findings come in according with a study found in India among 500 subject in 2013 with similar study population reported a prevalence of obstructive CAD 55.8\% and normal coronaries 44.2\% [23]. Traditional cardiac risk factors are highly prevalent in women. In our study, women with CAD have high distribution of Hypertension (58.6\%), with a risk of 2.1. According to a previous review article, hypertension is associated with two fold to threefold increase risk to develop CAD. The same finding was reported by Wenger where prevalence of hypertension increase with age and reach $65 \%$ in women with age $>65$ years [24]. This could be explained by the fact that hypertension is associated with adverse changes in the structure and function of arterial walls lead to Left ventricular hypertrophy and Ischemia [25]. Diabetes mellitus is the most important risk factor for CAD, the presence of diabetes in women increasing CAD risk by 3 - 7 folds compared to $2-3$ folds increase in diabetic men [26]. In our study, diabetes was two times higher in women with CAD compared with normal coronaries, Logistic regression shows that diabetes is working on CAD independently from others factors including in the model. In addition, different study showed that women with diabetes have a greater than three fold increase in CAD risk than non-diabetic women [26] [27], and CAD mortality in women is 3 - 5 times higher in diabetic compared to non-diabetic [24] [28] and 3-fold higher relative risk for all cardiovascular mortality in women 
compared with men [29]. Furthermore, Diabetes is a predictor of atypical presentation of acute myocardial infarction in women and different researches suggests that shortness of breath may be an important acute coronary syndrome symptom in women with diabetics [30] [31]. These two risk factors were found in Palestinian study in 2013 in patients with CAD that showed high prevalence of hypertension and diabetes in women 74.3\%, 65.7\% respectively [32]. Regarding the obesity, the majorities of our study population are obese and has BMI more than $35 \mathrm{~kg} / \mathrm{m}^{2}$, and obese women are at higher risk for CAD than overweight but the differences were not statistically significant, probably due to Sedentary, Poor diet, and economic crisis. In United state (USA), 22\% to 37\% of women are obese (BMI $>30)$, and $7 \%$ having a BMI $\geq 40 \mathrm{~kg} / \mathrm{m}^{2}$ [33], Increase weight is positively associated with increase CAD risk and mortality in women [33] [34]. Nurses' health study demonstrated a strong positive relation between obesity and risk of CHD during 14 years of follow-up [35]. In the Framingham heart study, obesity increases the risk of CAD by $64 \%$ in women, as opposed to $46 \%$ in male [36]. High levels of triglyceride are a significant risk factor of cardiovascular disease in both sexes, but more for women [37]. Reardom et al. found that plasma concentration accounted for $16 \%$ of the variation in scores for the severity of atherosclerosis in women [37]. Elevated TG has been shown to be a greater risk to women than men [17] [24] [38] [39]. All these data are in line with our results that shows high level of TG In patents wit documented CAD. Other risk factors are unique for women such as menopause; the average age of menopause worldwide is 52 years [24], and the risk of angina increases in menopause women when it occurs early [40]. Our data showed that $85.2 \%$ of study population was menopause and the prevalence was higher in CAD group with a risk of 3.2, controlling for age by logistic regression reduce the role of menopause as a risk factors for CAD and kept age as the main risk factor. Impaired left ventricular systolic function and electro cardiogram, abnormality analyses are more prevalent in our results among patient with CAD with a risk of 2.5 approximately.

Symptoms in women undergoing coronary angiography constitute a serious clinical scenario, in other hand, women with typical or atypical chest pain symptomatic (non-evectional or prolonged discomfort unrelieved by rest) have calculated obstructive CAD less than men [41], and 50\% of them do not have obstructive CAD [20] [42]. The most common presentation of obstructive coronary heart for women is atypical symptoms such as dyspnea, palpitation weakness, indigestion, and chest pain as a feeling of fullness [43] [44]. Most of these patients with normal coronaries, the chest pain can be attributed to syndrome X caused by micro vascular dysfunction, which is present in one-half of women with chest pain [45]. Chest pain typical of angina pectoris is less likely to be associated with obstructive CAD in women than men [40] [46]. For example, a study done in cardiothoracic center in London shows that $41 \%$ of women referred for chest pain, who underwent coronary angiography were found to have normal coronaries arteries compared with only $8 \%$ of male referred for similar circumstances [47]. Also in CASS study (coronary artery surgery study) include multicenter and randomized controlled clinical trial demonstrate that $50 \%$ of women undergoing coronary angiography for chest pain had either minimal or normal coronary artery narrowing [48]. In 1997, a study among population based registry of Coronary heart disease events in Jerusalem provide specific data showed that the rate of acute coronary events in Palestinian women were 2 - 4 times those in Jewish women living in Jerusalem, Palestinian women had an increase risk to acute coronary events with Normal coronary angiography [49]. In a recent study from 600 USA hospitals (2008), in patients with ACS, the risk for obstructive CAD were $50 \%$ lower for women compared with male [50]. Reis et al. and WISE studies demonstrated that micro vascular dysfunction could be identified in a large cohort of women (50\%) with chest pain in the absence of coronary lesion due to abnormal endothelial function [44] [49]. Notably, a recent study demonstrated that 30\% of women with chest pain, normal coronaries and endothelial dysfunction develop obstructive CAD during 10 years follow up [50]. For female with ACS or STEMI $10 \%$ to $25 \%$ have no obstructive CAD [51]-[53]. Our data are in line with previous studies cited and demonstrated that women presented with atypical symptoms have 95.7\% normal coronaries, in opposite patients with documented (Clinical, ECG, ECHO) ACS such as myocardial infarction, unstable angina and stable chronic angina has significant coronary lesion. However, non-cardiac reasons for chest discomfort should be evaluated only after coronary disease has been ruled out [54]. More than $80 \%$ of middle women have more than one, traditional risk factors [55]. In our study population (12.2\%, 27.9\%, 57.6\%) respectively have one, two, more than three risk factors and only $2.6 \%$ without risk factors. Significant CAD is seen in 55\% of women with more than 2 risk factors in study done by Dave et al, among Indian women undergoing CAG and showed greater proportion of three-vessel disease (39.6\%) than two vessel diseased (12.9\%) and single vessel disease (15.8\%) [56]. In contrast, our study shows that multivessels diseases (more than 2 vessels) are presents in patients who have more than three risk factors and suffering from unstable angina. 


\section{Limitation of Study}

This study was a record based for the available risk factors in patients file that could be exposed for in accuracy of the results recording. Our second limitation was inclusion of Cigarette smoking because it is not accepted practice for women in our society.

\section{Conclusion}

Women affected by CAD are of great concern; more researches are needed to understand how this disease affects women and how morbidity can be presented in our population. Education early, aggressive control of risk factors, rapid access to diagnosis and serious treatment need to prevent cardiovascular events and will directly benefit women so further benefits to male.

\section{References}

[1] Fleischmann, K.E., Hunink, M.G. and Kuntz, K.M. (1998) Exercise Echocardiography or Exercise SPECT Imaging? A Meta-Analysis of Diagnostic Test Performance. Journal of the American Medical Association, 280, 913-920. http://dx.doi.org/10.1001/jama.280.10.913

[2] Healy, B. (1991) The Yentl Syndrome. The New England Journal of Medicine, 325, 274-276. http://dx.doi.org/10.1056/NEJM199107253250408

[3] Gurwitz, J.H., Col, N.F. and Avom, J. (1992) The Exclusion of the Elderly and Women from Clinical Trials in Myocardial Infarction. Journal of the American Medical Association, 268, 1417-1422. http://dx.doi.org/10.1001/jama.1992.03490110055029

[4] Roger, V.L., Go, A.S. and Lloyd-Jones, D.M. (2012) American Heart Association Statistics Committee and Stroke Statistics Subcommittee. Heart Disease and Stroke Statistics 2012 Update: A Report from the American Heart Association. Circulation, 125, 188-197. http://dx.doi.org/10.1161/CIR.0b013e3182456d46

[5] Petersen, S., Peto, V., Rayner, M., Leal, J., Luengo-Fernandez, R. and Gray, A. (2005) European Cardiovascular Disease Statistics. British Heart Foundation, London.

[6] Ni, H., Coady, S. and Rosamond, W. (2009) Trends from 1987 to 2004 in Sudden Death Due to Coronary Heart Disease: The Atherosclerosis Risk in Communities (ARIC) Study. American Heart Journal, 157, 46-52. http://dx.doi.org/10.1016/j.ahj.2008.08.016

[7] Ministry of Health, PHIC (2014) Health Status in Palestine 2013. 49.

[8] Wenger, N.K., Speroff, L. and Packard, R. (1993) Cardiovascular Health and Disease in Women. The New England Journal of Medicine, 329, 247-256. http://dx.doi.org/10.1056/NEJM199307223290406

[9] Centers for Disease Control and Prevention (1999) State-Specific Mortality from Sudden Cardiac Death-United States. http://www.cdc.gov/mmwr/preview/mmwrhtml/mm5106a

[10] O’Connor, G.T., Morton, J.R. and Diehl, M.J. (1993) Differences between Men and Women in Hospital Mortality Associated with Coronary Artery Bypass Graft Surgery. Circulation, 88, 2104-2110. http://dx.doi.org/10.1056/NEJM199307223290406

[11] Ayanian, J.Z. and Epstein, A.M. (1991) Differences in the Use of Procedures between Women and Men Hospitalized for Coronary Heart Disease. The New England Journal of Medicine, 325, 221-225. http://dx.doi.org/10.1056/NEJM199107253250401

[12] Steingart, R.M., Packer, M., Hamm, P., Coglianese, M.E., Gersh, B. and Geltman, E.M. (1991) Sex Differences in the Management of Coronary Artery Disease. The New England Journal of Medicine, 325, 226-230. http://dx.doi.org/10.1056/NEJM199107253250402

[13] Rathore, S.S., Chen, J., Wang, Y., Radford, M.J., Vaccarino, V. and Krumholz, H.M. (2001) Sex Differences in Cardiac Catheterization: The Role of Physician Gender. Journal of the American Medical Association, 286, 2849-2856. http://dx.doi.org/10.1001/jama.286.22.2849

[14] Nguyen, J.T., Berger, A.K., Duval, S. and Luepker, R.V. (2008) Gender Disparity in Cardiac Procedures and Medication Use for Acute Myocardial Infarction. American Heart Journal, 155, 862-868. http://dx.doi.org/10.1016/j.ahj.2007.11.036

[15] Shaw, L.J., Merz, C.N. and Pepine, C.J. (2006) The Economic Burden of Angina in Women with Suspected Ischemic Heart Disease: Results from the National Institutes of Health-National Heart, Lung, and Blood Institute-Sponsored Women's Ischemia Syndrome Evaluation. Circulation, 114, 894-904. http://dx.doi.org/10.1161/CIRCULATIONAHA.105.609990

[16] Hemingway, H., Crook, A.M. and Feder, G. (2001) Underuse of Coronary Revascularization Procedures in Patients 
Considered Appropriate Candidates for Revascularization. The New England Journal of Medicine, 344, 645-654. http://dx.doi.org/10.1056/NEJM200103013440906

[17] Lerner, D.J. and Kannel, W.B. (1986) Patterns of Coronary Heart Disease Morbidity and Mortality in the Sexes: A 26-Year Follow-Up of the Framingham Population. American Heart Journal, 111, 383-390. http://dx.doi.org/10.1016/0002-8703(86)90155-9

[18] Limacher, M. and Handberg, E. (2002) Evaluating Women with Chest Pain for the Diagnosis of Coronary Artery Disease. Disease-a-Month, 48, 647-658.

[19] Lloyd-Jones, D.M., Leip, E.P. and Larson, M.G. (2006) Prediction of Lifetime Risk for Cardiovascular Disease by Risk Factor Burden at 50 Years of Age. Circulation, 113, 791-798. http://dx.doi.org/10.1161/CIRCULATIONAHA.105.548206

[20] Sharaf, B.L., Pepine, C.J. and Kerensky, R.A. (2001) Detailed Angiographic Analysis of Women with Suspected Ischemic Chest Pain Pilot Phase Data from the NHLBI-Sponsored Women's Ischemia Syndrome Evaluation WISE Study Angiographic Core Laboratory. American Journal of Cardiology, 87, 937-941. http://dx.doi.org/10.1016/S0002-9149(01)01424-2

[21] Vaccarino, V., Parsons, L., Every, N.R., Barron, H.V. and Krumholz, H.M. (1999) Sex Based Differences in Early Mortality after Myocardial Infarction. New England Journal of Medicine, 341, 217-225. http://dx.doi.org/10.1056/NEJM199907223410401

[22] Colditz, G.A., Stampfer, M.J., Willett, W.C., Rosner, B., Speizer, F.E. and Hennekens, C.H. (1986) A Prospective Study of Parental History of Myocardial Infarction and Coronary Heart Disease in Women. American Journal of Epidemiology, 123, 48-58.

[23] Ezhumalai, B. and Jayaraman, B. (2014) Angiographic Prevalence and Pattern of Coronary Artery Disease in Women. Indian Heart Journal, 66, 422-426.

[24] Wenger, N.K. (2003) Coronary Heart Disease: The Female Heart Is Vulnerable. Progress in Cardiovascular Diseases, 46, 199-229. http://dx.doi.org/10.1016/j.pcad.2003.08.003

[25] Liao, Y., Cooper, R.S., Mensah, G.A. and McGee, D.L. (1995) Left Ventricular Hypertrophy Has a Greater Impact on Survival in Women than in Men. Circulation, 92, 805-810. http://dx.doi.org/10.1161/01.CIR.92.4.805

[26] Huxley, R., Barzi, F. and Woodward, M. (2006) Excess Risk of Fatal Coronary Heart Disease Associated with Diabetes in Men and Women: Meta-Analysis of 37 Prospective Cohort Studies. British Medical Journal, 332, 73-78. http://dx.doi.org/10.1136/bmj.38678.389583.7C

[27] Spencer, E.A., Pirie, K.L. and Stevens, R.J., Million Women Study Collaborators (2008) Diabetes and Modifiable Risk Factors for Cardiovascular Disease: The Prospective Million Women Study. European Journal of Epidemiology, 23, 793-799. http://dx.doi.org/10.1007/s10654-008-9298-3

[28] Kannel, W.B. (2002) The Framingham Study: Historical Insight on the Impact of Cardiovascular Risk Factors in Men versus Women. The Journal of Gender-Specific Medicine, 5, 27-37.

[29] Barrett-Connor, E.L., Cohn, B.A. and Wingard, D.L. (1991) Why Is Diabetes Mellitus a Stronger Risk Factor for Fatal Ischemic Heart Disease in Women than in Men? The Rancho Bernardo Study. Journal of the American Medical Association, 265, 627-631. http://dx.doi.org/10.1001/jama.1991.03460050081025

[30] Stephen, S.A., Darney, B.G. and Rosenfeld, A.G. (2008) Symptoms of Acute Coronary Syndrome in Women with Diabetes: An Integrative Review of the Literature. Heart Lung, 37, 179-189. http://dx.doi.org/10.1016/j.hrtlng.2007.05.006

[31] Culic, V., Eterovic, D., Miric, D. and Silic, N. (2002) Symptom Presentation of Acute Myocardial Infarction: Influence of Sex, Age, and Risk Factors. American Heart Journal, 144, 1012-1017.

[32] Jamee, A., Abed, Y. and Jalambo, M.O. (2013) Gender Difference and Characteristics Attributed to Coronary Artery Disease in Gaza-Palestine. Global Journal of Health Science, 5, 51-56. http://dx.doi.org/10.5539/gjhs.v5n5p51

[33] Ogden, C.L., Carroll, M.D., Curtin, L.R., McDowell, M.A., Tabak, C.J. and Flegal, K.M. (2006) Prevalence of Overweight and Obesity in the United States, 1999-2004. Journal of the American Medical Association, 295, 549-555. http://dx.doi.org/10.1001/jama.295.13.1549

[34] Jousilahti, P., Tuomilehto, J., Vartiainen, E., Pekkanen, J. and Puska, P. (1996) Body Weight, Cardiovascular Risk Factors, and Coronary Mortality: 15-Year Follow-Up of Middle-Aged Men and Women in Eastern Finland. Circulation, 93, 1372-1379. http://dx.doi.org/10.1161/01.CIR.93.7.1372

[35] Willett, W.C., Manson, J.E. and Stampfer, M.J. (1995) Weight, Weight Change, and Coronary Heart Disease in Women: Risk within the "Normal” Weight Range. Journal of the American Medical Association, 273, 461-465.

http://dx.doi.org/10.1001/jama.1995.03520300035033

[36] Wilson, P.W., D’Agostino, R.B., Sullivan, L., Parise, H. and Kannel, W.B. (2002) Overweight and Obesity as Deter- 
minants of Cardiovascular Risk: The Framingham Experience. Archives of Internal Medicine, 162, 1867-1872. http://dx.doi.org/10.1001/archinte.162.16.1867

[37] Reardon, M.F., Nestel, P.J., Craig, I.H. and Harper, R.W. (1985) Lipoprotein Predictors of the Severity of Coronary Artery Disease in Men and Women. Circulation, 71, 881-888. http://dx.doi.org/10.1161/01.CIR.71.5.881

[38] Hokanson, J.E. and Austin, M.A. (1996) Plasma Triglyceride Level Is a Risk Factor for Cardiovascular Disease Independent of High-Density Lipoprotein Cholesterol Level: A Meta-Analysis of Population-Based Prospective Studies. Journal of Cardiovascular Risk, 3, 213-219. http://dx.doi.org/10.1097/00043798-199604000-00014

[39] Reuterwall, C., Hallqvist, J. and Ahlbom, A. (1999) Higher Relative, but Lower Absolute Risks of Myocardial Infarction in Women than in Men: Analysis of Some Major Risk Factors in the SHEEP Study. Journal of Internal Medicine, 246, 161-174. http://dx.doi.org/10.1046/j.1365-2796.1999.00554.x

[40] Shaw, L.J., Bairey Merz, C.N., Pepine, C.J., Reis, S.E., Bittner, V. and Kelsey, S.F. (2006) Insights from the NHLBI-Sponsored Women's Ischemia Syndrome Evaluation (WISE) Study: Part I: Gender Differences in Traditional and Novel Risk Factors, Symptom Evaluation, and Gender Optimized Diagnostic Strategies. Journal of the American College of Cardiology, 47, 4-20. http://dx.doi.org/10.1016/j.jacc.2005.01.072

[41] Shaw, L.J. and Redberg, R.F. (2003) Clinical Risk Assessment in Women: Chest Discomfort. Report from the WISE Study. In: Shaw, L.J. and Redberg, R.F., Eds., CAD in Women: Evidence-Based Diagnosis and Treatment, Humana Press, Totowa, 129-142.

[42] Merz, N.B., Johnson, B.D. and Kelsey, P.S.F. (2001) Diagnostic, Prognostic, and Cost Assessment of Coronary Artery Disease in Women. The American Journal of Managed Care, 7, 959-965.

[43] Bairey Merz, C.N., Shaw, L.J., Reis, S.E., Bittner, V., Kelsey, S.F. and Olson, M. (2006) Insights from the NHLBI-Sponsored Women’s Ischemia Syndrome Evaluation (WISE) Study: Part II: Gender Differences in Presentation, Diagnosis, and Outcome with Regard to Gender-Based Pathophysiology of Atherosclerosis and Macrovascular and Microvascular Coronary Disease. Journal of the American College of Cardiology, 47, 21-29. http://dx.doi.org/10.1016/j.jacc.2004.12.084

[44] DeVon, H.A., Ryan, C.J., Ochs, A.L. and Shapiro, M. (2008) Symptoms across the Continuum of Acute Coronary Syndromes: Differences between Women and Men. American Journal of Critical Care, 17, 14-24.

[45] Reis, S.E., Holubkov, R., Conrad Smith, A.J., Kelsey, S.F., Sharaf, B.L. and Reichek, N. (2001) Coronary Microvascular Dysfunction Is Highly Prevalent in Women with Chest Pain in the Absence of Coronary Artery Disease: Results from the NHLBI WISE Study. American Heart Journal, 141, 735-741. http://dx.doi.org/10.1067/mhj.2001.114198

[46] Milner, K.A., Funk, M., Arnold, A. and Vaccarino, V. (2002) Typical Symptoms Are Predictive of Acute Coronary Syndromes in Women. American Heart Journal, 143, 283-288. http://dx.doi.org/10.1067/mhj.2002.119759

[47] Sullivan, A.K., Holdright, D.R., Wright, C.A., Sparrow, J.L., Cunningham, D. and Fox, K.M. (1994) Chest Pain in Women: Clinical, Investigative, and Prognostic Features. British Medical Journal, 308, 883-886. http://dx.doi.org/10.1136/bmj.308.6933.883

[48] Kennedy, J.W., Killip, T., Fisher, L.D., Alderman, E.L., Fillespie, M.J. and Monk, M.B. (1982) The Clinical Spectrum of Coronary Artery Disease and Its Surgical and Medical Management, 1974-1979. The Coronary Artery Surgery Study. Circulation, 66, 16-23.

[49] Kark, J.D., Fink, R., Adler, B., Goldberger, N. and Goldman, S. (2006) The Incidence of Coronary Heart Disease among Palestinians and Israelis in Jerusalem. International Journal of Epidemiology, 35, 448-457. http://dx.doi.org/10.1093/ije/dyl012

[50] Shaw, L.J., Shaw, R.E., Merz, C.N.B., Brindis, R.G., Klein, L.W., Nallamothu, B., et al. (2008) Impact of Ethnicity and Gender Differences on Angiographic Coronary Artery Disease Prevalence and In-Hospital Mortality in the American College of Cardiology-National Cardiovascular Data Registry (ACC-NCDR). Circulation, 117, 1787-1801. http://dx.doi.org/10.1161/CIRCULATIONAHA.107.726562

[51] Bugiardini, R., Manfrini, O., Pizzi, C., Fontana, F. and Morgagni, G. (2004) Endothelial Function Predicts Future Development of Coronary Artery Disease. A Study on Women with Chest Pain and Normal Angiograms. Circulation, 109, 2518-2523. http://dx.doi.org/10.1161/01.CIR.0000128208.22378.E3

[52] Bugiardini, R. and Bairey Merz, C.N. (2005) Angina with "Normal” Coronary Arteries: A Changing Philosophy. Journal of the American Medical Association, 293, 477-484. http://dx.doi.org/10.1001/jama.293.4.477

[53] Hochman, J.S., McCabe, C.H. and Stone, P.H. (1997) Outcome and Profile of Women and Men Presenting with Acute Coronary Syndromes: A Report from TIMI IIIB. Journal of the American College of Cardiology, 30, 141-148. http://dx.doi.org/10.1016/S0735-1097(97)00107-1

[54] Buchthal, S.D., den Hollander, J.A. and Merz, C.N. (2000) Abnormal Myocardial Phosphorous-31 Nuclear Magnetic Resonance Spectroscopy in Women with Chest Pain but Normal Coronary Angiograms. The New England Journal of Medicine, 342, 829-835. http://dx.doi.org/10.1056/NEJM200003233421201 
[55] Mokdad, A.H., Ford, E.S. and Bowman, B.A. (2001) Prevalence of Obesity, Diabetes, and Obesity-Related Health Risk Factors. Journal of the American Medical Association, 289, 76-79.

[56] Dave, T.H., Wasir, H.S. and Prabhakaran, D. (1991) Profile of Coronary Artery Disease in Indian Women: Correlation of Clinical, Non Invasive and Coronary Angiographic Findings. Indian Heart Journal, 43, 25-29. 
Scientific Research Publishing (SCIRP) is one of the largest Open Access journal publishers. It is currently publishing more than 200 open access, online, peer-reviewed journals covering a wide range of academic disciplines. SCIRP serves the worldwide academic communities and contributes to the progress and application of science with its publication.

Other selected journals from SCIRP are listed as below. Submit your manuscript to us via either submit@scirp.org or Online Submission Portal.
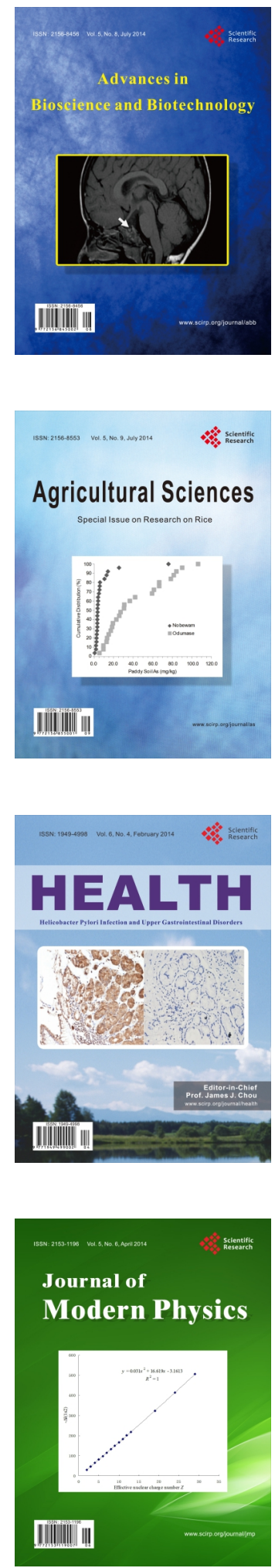
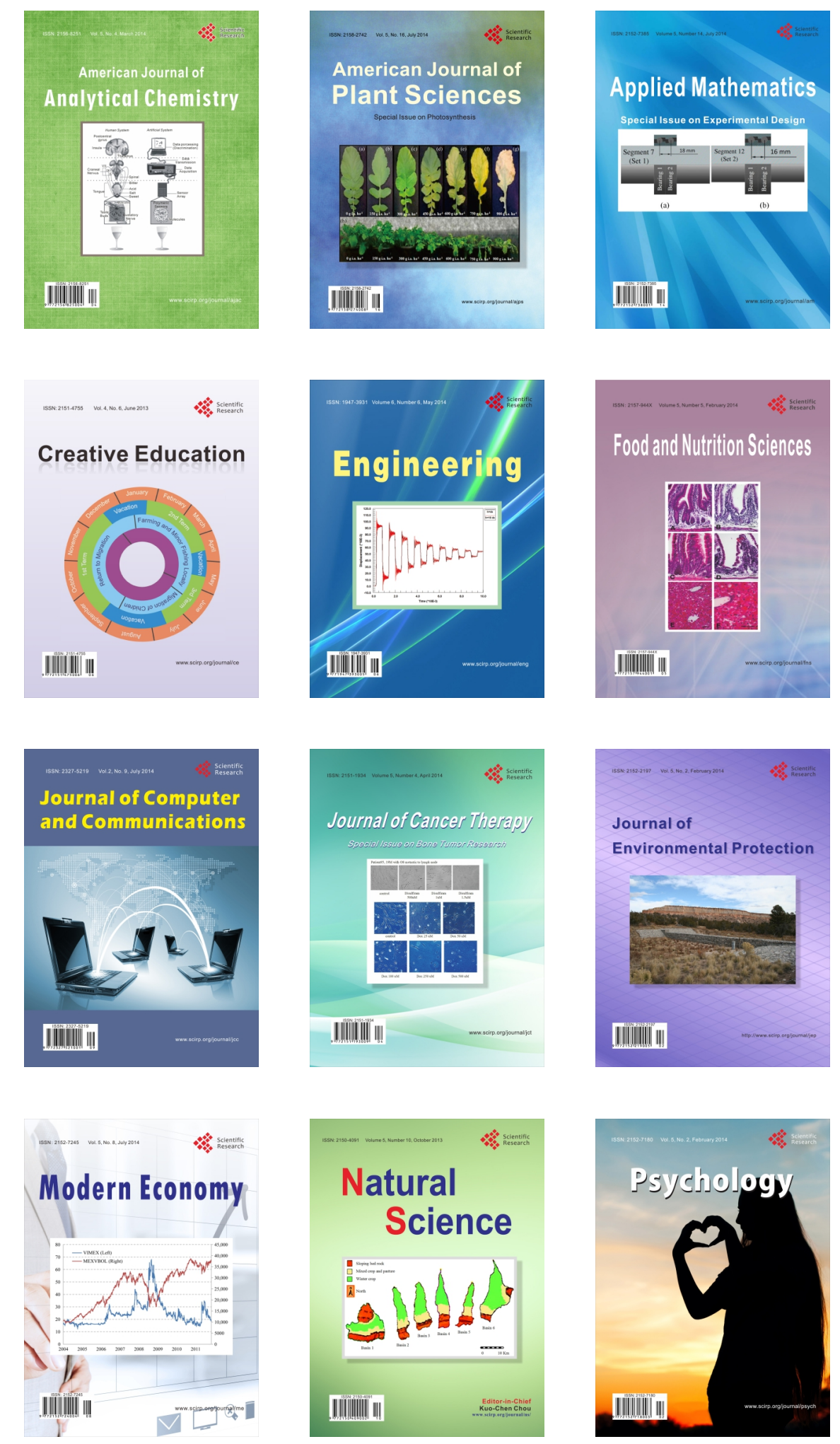